\title{
Effect of activated sealant water on strength of cement samples
}

\author{
Elvira Egereva ${ }^{1 *}$, Alexei Barmenkov ${ }^{2}$, and Alina Barmenkova ${ }^{2}$ \\ ${ }^{1}$ Moscow State University of Civil Engineering, 26, Yaroslavskoe shosse, 129337, Moscow, Russia \\ ${ }^{2}$ National Research Mordovia State University, MRSU, 68, Bolshevistskaya str., 430005, Saransk, \\ Republic of Mordovia
}

\begin{abstract}
The article presents the results of optimization of the cement composition according to the criteria of compressive strength and bending by methods of mathematical planning of the experiment. As a result of the studies, cement compositions of increased strength were obtained using activated closure water, as well as using tandem activated water $(\mathrm{AB})+$ plasticizer and $\mathrm{AB}+$ adhesive additive. At optimal content of components, strength gain of up to $18 \%$ is achieved.
\end{abstract}

\section{Introduction}

One of the promising technological methods of producing concretes with improved physical, technical and operational properties is the use of activated natural-mineralized water during their preparation. This area is currently not widely used due to unstable results obtained in laboratory and production conditions using standard water activation devices. This problem can be solved with modern equipment that allows you to control the activation process and obtain water with given properties.

\section{Materials and methods}

The purpose of the research is scientific justification and practical use of techniques and methods for improving the physical and technical properties of cement concretes and construction products based on them using aqueous solutions activated by electrochemical and electromagnetic methods used for closure [1-3].

For verification of this theory we used the device of electromagnetic protivonakipny water treatment UPOVS-2/5.0 Maksmir. The activation of water for the closure of cement compositions, solution and concrete mixtures was carried out by three methods: treatment with an electromagnetic field, electric current and the combined action of an electromagnetic field and electric current.

Portland cement of PTs-400 D0 OJSC "Mordovcement" GOST 10178-85, the following chemical composition: $\mathrm{SiO} 2$ - 23.08, $\mathrm{Al} 2 \mathrm{O} 3$ - 5.45, Fe2O3 - 2.99, $\mathrm{CaO}$ - 66.91, $\mathrm{MgO}$ -

\footnotetext{
* Corresponding author: egerevaen@mail.ru
} 
1.42 , SO3 -0.15 and the main physical characteristics: true density $-3.10 \mathrm{~g} / \mathrm{cm} 3$, average density $-1.10 \mathrm{~g} / \mathrm{cm} 3$, specific surface area $-3100 \mathrm{~cm} 2 / \mathrm{g}$, was used as a binder.

Ordinary drinking water according to GOST 23732-79 was used to fill concretes and solutions.

As chemical additives, an additive of cellulose ether for concretes and solutions "Mecellose 22501" (GOST 31357 - 2007) and a plasticizer "MelFlux PP100F" (GOST 24211-2003) manufactured by CJSC EuroChem-1 were used.

In accordance with GOST 24211-03 "Additives for concrete and mortar. The general technical requirements MelFlux PP100F comply with the requirements for the superplasticizer and hardening accelerator and is a complex product. The chemical composition of MelFlux PP100F: - a powder product obtained by spray drying, based on modified polyethylene glycol. Technical data: form - yellowish powder; bulk density - 300$500 \mathrm{~g} / 1$; heat loss - max. $2.0 \% ; 20 \%$ solution at $200 \mathrm{~S}$ has $\mathrm{pH}=6.5-8.5$; Features: highly effective dispersant; reduces shrinkage; effective in a wide temperature range

Composition and properties of Mecellose 22501: Hydroxyethyl cellulose (HEC). Nonionogenic. Moisture content - not more than 5\%. Particle size $<425 \mathrm{~km}$ - not less than $90 \%$. Viscosity of $2 \%$ aqueous solution based on dry weight, $20^{\circ} \mathrm{C}$, in water with a hardness of $20^{\circ} \mathrm{C}, 250-550 \mathrm{mPa} * \mathrm{~s}$ (Brookfeld). Whitish powder, soluble in water.

\section{Results}

Consider the tensile strength of cement samples based on activated water during bending. Figure 1 shows the dependence of flexural tensile strength on the age of samples in days. Based on the results of the tests, it can be concluded that there are compositions whose results exceed the strength readings of the composition based on unactivated water. Consider the strength set of each composition. We will analyze the tensile strength of the samples during bending.

The composition based on unactivated water was a control. Its strength did not fall, according to the theoretical model, more than $80 \%$ of the strength was gained in the first week. Then there was a stable increase in strength from $15 \mathrm{MPa}$ to $16 \mathrm{MPa}$.

Based on the above, it can be concluded that the compositions M3E3, M3E1, M1 and E1M3 are most stable and with increased strength. This also includes the composition of E1, which on the 7th and 14th days showed a strength less than the selected optimal compositions, but on the 28th day he "caught up" with them. Its strength was 18.1 MPa.

Consider the strength of cement samples based on activated compression. Figure 2 shows the dependence of the compression strength of cement samples on the age of the samples in days. Based on the results of the tests, it can be concluded that there are compositions whose results exceed the strength of the composition, based on unactivated water. Consider the strength set of each composition [4-7].

We will analyze the compression strength of the samples. It can be concluded that the compositions M3E1 and E1M3 are most stable and with an increase in compression strength. The strength gain over the unactivated water composition is $28 \%$ and $20 \%$. The compositions E5, M1, E3, M3, E3M3 and M3E5 also show good results with an increase in strength of $11 \%$ to $18 \%$.

Thus, based on the tests performed, it can be concluded that the compositions E1M3 and M3E1 have the best values of bending tensile strength, as well as compression.

Moreover, the compression strength gain of the composition E1M3 is $28 \%$, and the bending is $12 \%$, and the compression strength gain of the composition M3E1 is $20 \%$, and the bending is $11 \%$. The compositions M1 and E3M3 have quite good properties. 


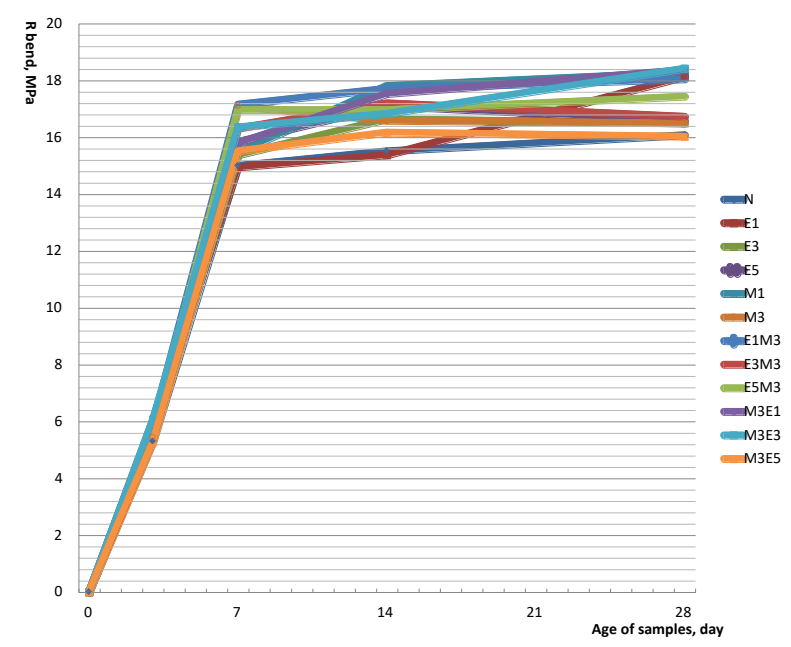

Fig. 1. Tensile strength of cement samples bending $f(x)=\operatorname{Rig}(t)$.

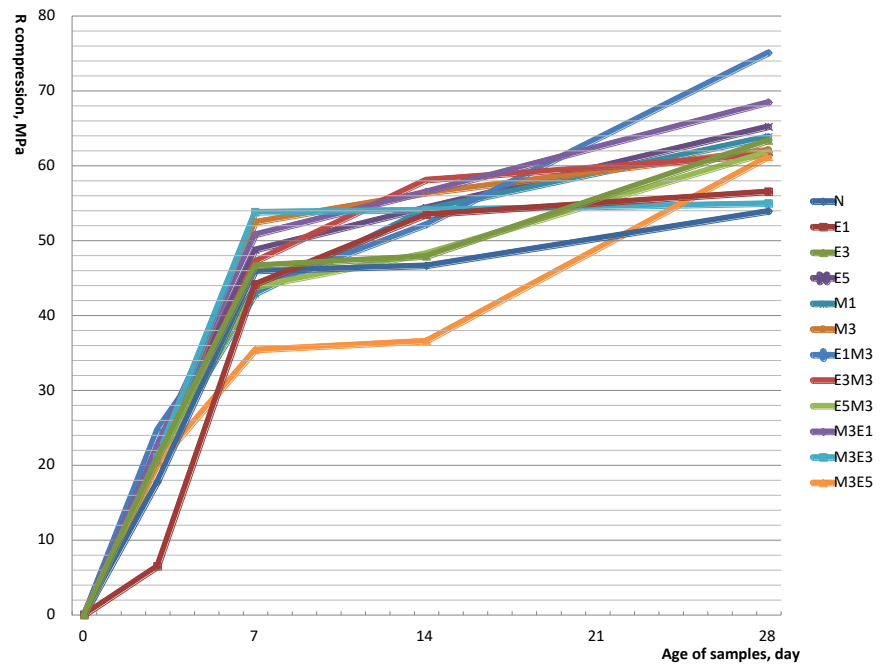

Fig.2. Strength of cement samples compression $f(x)=\operatorname{Rcg}(t)$.

It can be concluded that the composition of the E1M3 is the most optimal and stably working for both bending tension and compression. The increase in tensile strength during bending is $14 \%$, and for compression $-27 \%$.

One way to improve the physical and technical properties of concrete cmes is to introduce plasticizers and additives into their composition. In this regard, the influence of water activation conditions on the physical and mechanical properties of cement composites containing a plasticizer and an additive would be studied.

On the basis of numerous tests, we built the dependencies of strength characteristics on the mode of activation of the closure water during the period. 
We will consider durability of cement samples on the basis of the activated zatvoreniye water with addition of MelFlux PP100F softener on stretching at a bend. Figure 3 shows the dependence of flexural tensile strength on the age of samples in days.

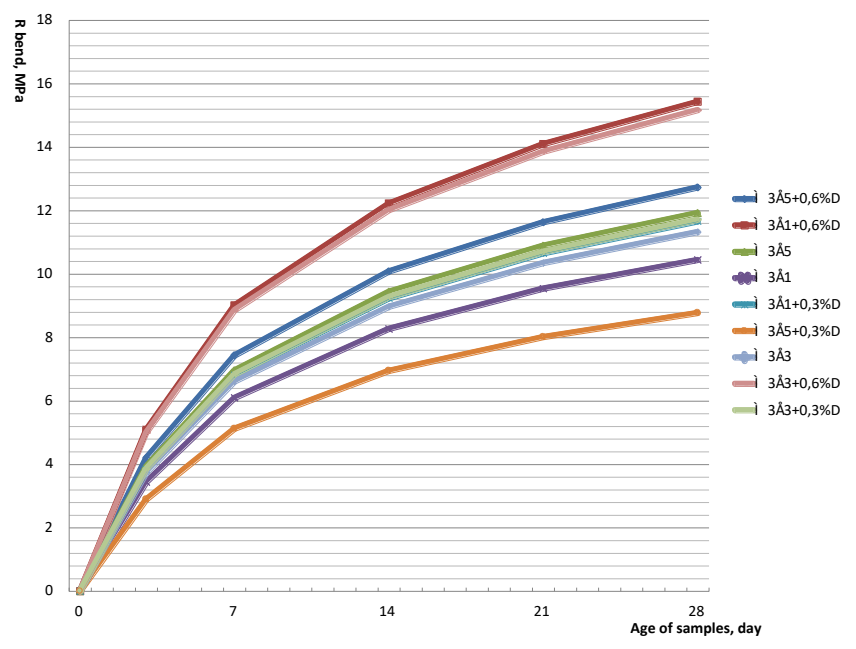

Fig. 3. Tensile strength of cement specimens during bending $f(x)=$ Rizg $(t)$ plasticizer - MelFlux PP100F.

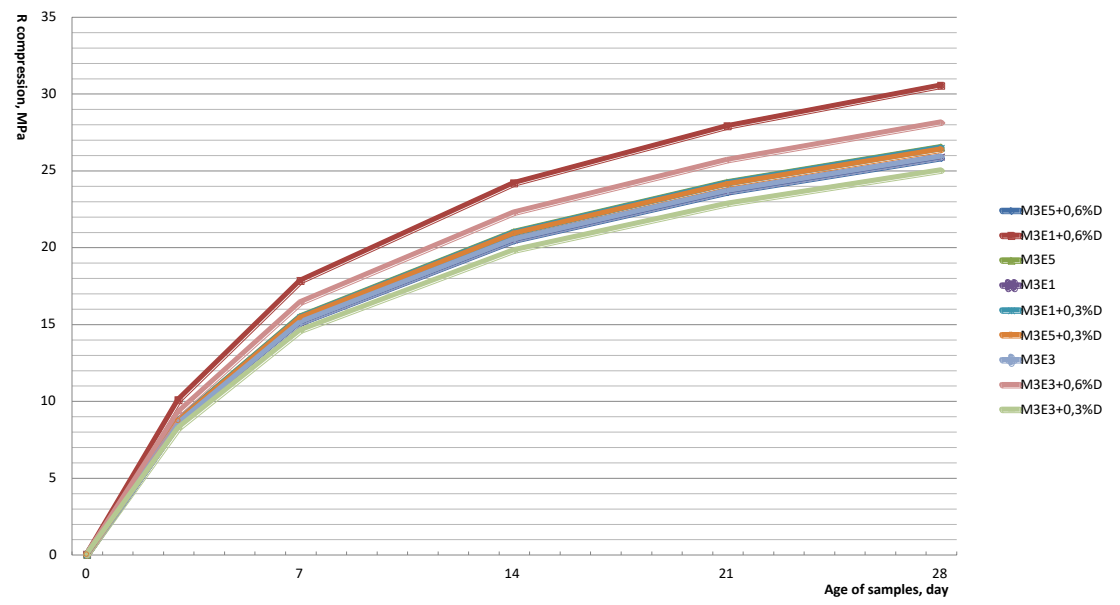

Fig. 4. Strength of cement samples for compression $f(x)=R c g(t)$ plasticizer - MelFlux PP100F.

Based on the results of the tests, it can be concluded that there are compositions whose results exceed the strength of the composition based on activated water without taking into account the effect of the plasticizer. Consider the strength set of each composition. We will analyze the tensile strength of the samples during bending.

Throughout the observation time, all compositions steadily gain strength in proportion to the theoretical model, no jumps and drops are observed. Let's consider the value of strength indices for 28 days. The results of the compositions M3E1 + 0,6D and M3E3 + $0,6 \mathrm{D}$ are pronounced. Which show a maximum tensile strength of $15.6 \mathrm{MPa}$ and $15.2 \mathrm{MPa}$, respectively. 
The average values for tensile bending strength are the compositions: M3E5 + 0.6D, M3E5, M3E3 + 0.3D, M3E1 + 0.3D, M3E3 and M3E1. The strength of the compositions ranges from 10.2 $\mathrm{MPa}$ to $12.8 \mathrm{MPa}$.

The lowest results show the composition of M3E5 + 0.3D. Its tensile strength is 8.8 MPa.

We will consider durability of cement samples on the basis of the activated zatvoreniye water with addition of MelFlux PP100F softener on compression. Figure 4 shows the dependence of compressive strength on the age of samples in days.

Throughout the observation time, all compositions steadily gain strength in proportion to the theoretical model, no jumps and drops are observed. Let's consider the value of strength indices for 28 days. Pronounced are the results of the composition M3E1 + 0,6D. Its compressive strength readings are a maximum compressive strength of $30.5 \mathrm{MPa}$.

Average values on durability on compression structures possess: M3E3+0.6D, M3E5, M3E5+0.3D, M3E1+0.3D, M3E3, M3E1, M3E5+0.6D. The strength of the compositions ranges from $25.5 \mathrm{MPa}$ to $28 \mathrm{MPa}$.

The worst results showed the composition of $\mathrm{M} 3 \mathrm{E} 3+0.3 \mathrm{D}$. Its compressive strength is $24 \mathrm{MPa}$.

We will carry out statistical data processing in order to identify the optimal composition with the activation mode and the content of the plasticizer.

In this regard, at the second stage, studies were carried out on the properties of cement composites from the type and quantitative content of additives, as which the plasticizer "MelFlux PP100F" and the complex additive "Mesellose 22501" were chosen. Studies were carried out using methods of mathematical planning of the experiment. The Kono plan with the number of experiments equal to 9 was selected as the planning matrix. Variable factors were: Kh1 - current intensity on the electric activator; Kh2 is the amount of additive. To activate the closure water, the Maksmir UPOVS-2/5.0 apparatus was used. Activation was carried out according to the mode: the joint effect was initially a magnet, and then a variable electric activator. The planning matrix and the operating matrix are shown in Table 1.

Table 1. Planning Matrix and Work Matrix.

\begin{tabular}{|c|c|c|c|c|}
\hline \multirow{2}{*}{$\begin{array}{c}\text { No } \\
\text { experience }\end{array}$} & \multicolumn{2}{|c|}{ Planning Matrix } & \multicolumn{2}{c|}{ Working matrix } \\
\cline { 2 - 5 } & $\mathrm{x}_{1}$ & $\mathrm{x}_{2}$ & $\mathrm{x}_{1}$ & $\mathrm{x}_{2}$ \\
\hline 1 & +1 & +1 & $\mathrm{E} 5$ & 0.6 \\
\hline 2 & -1 & +1 & $\mathrm{E} 1$ & 0.6 \\
\hline 3 & +1 & -1 & E5 & 0 \\
\hline 4 & -1 & -1 & $\mathrm{E} 1$ & 0 \\
\hline 5 & -1 & 0 & E1 & 0.3 \\
\hline 6 & +1 & 0 & E5 & 0.3 \\
\hline 7 & 0 & -1 & E3 & 0 \\
\hline 8 & 0 & +1 & E3 & 0.6 \\
\hline 9 & 0 & 0 & E3 & 0.3 \\
\hline
\end{tabular}

After testing and statistical processing of the results of the experiment, regression equations were obtained showing the dependence of the change in bending strength and compression.

Based on the planning matrix, we obtain a 2-factor experiment with 2 variable factors: activation of water by alternating electric conditions (modes E1, E3, E5) with constant magnetic activation $\mathrm{M} 3$ = const - factorus $\mathrm{Kh} 1$ and the amount of plasticizer added $-\mathrm{Kh} 2$. Based on the obtained data using statistical data processing using a subprogram written in MS Excel 10, we obtain values of regression coefficients, substituting them and the equation we obtain a regression equation, the solution of which is the surface of Figure 5. 
Based on the obtained volumetric solution, we can judge the influence of each of the variable factors on the following value of Figure 6.

Polynomial model:

$$
\operatorname{Rsg}(\mathrm{y})=25.553-0.758 \cdot \mathrm{x}_{1}+0.379 \cdot \mathrm{x}_{2}-13.331 \cdot \mathrm{x}_{1} \cdot \mathrm{x}_{2}+0.308 \cdot \mathrm{x}_{1}{ }^{2}+1.471 \cdot \mathrm{x}_{2}{ }^{2}
$$

We will analyze Fig.5. As mentioned above, the surface shown in the figure is a solution to the regression equation, and therefore the value of the strength of the test samples under compression at the age of 28 days.

As can be seen from the graph, the maximum value of strength of cement particles during compression is achieved with water values $(<$ unk $>)=-1,<$ unk $><$ unk $>(<$ unk $>)=$ 1 , which is equal to Rsg $=29.8 \mathrm{MPa}$. With water values $(\mathrm{X} 1)=1$, MelFlux PP100F (X2) $=0.5$, the strength is $\mathrm{Rsg}=25.0 \mathrm{MPa}$, which corresponds to the minimum value.

Thus, the composition of M3E1 + 0.6D is optimal for cement samples.

The worst are the compositions: M3E5 + 0.3D and M3E5 + 0, 6D.

It can be concluded that the compositions M3E1 + 0.6D, M3E3 + 0.6D are the most optimal and stable for both bending tension and compression. The strength gain of the composition M3E1 + 0.6D for bending tension is $8 \%$, and for compression - $25 \%$. The strength gain of the composition M3E3 $+0.6 \mathrm{D}$ for bending tension is $14 \%$, and for compression - $18 \%$.

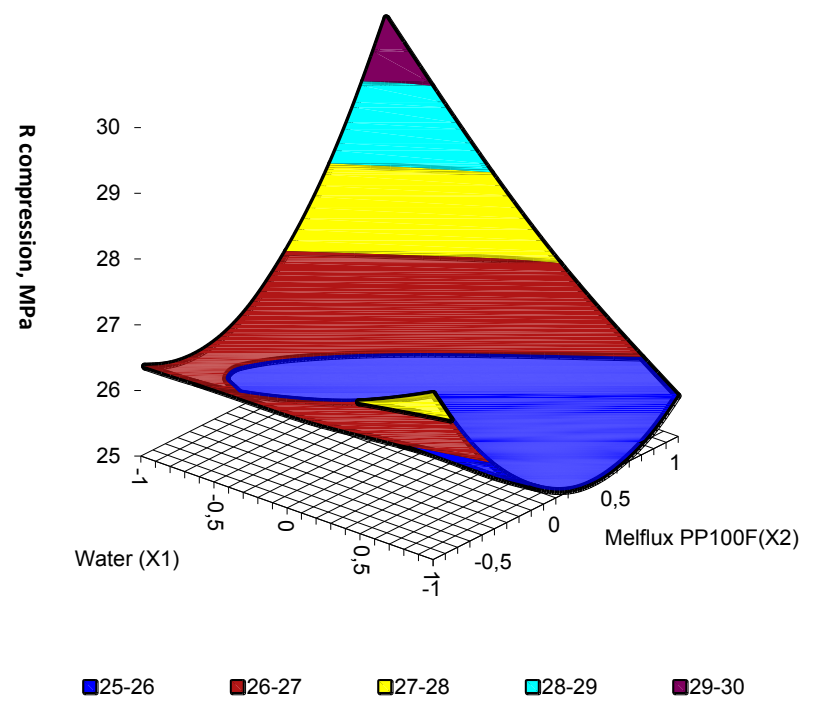

Fig. 5. Strength of cement samples under compression $\mathrm{f}(\mathrm{x})=\mathrm{Rcg}(\mathrm{t})$ plasticizer - MelFlux PP100F, 28 days $(3 \mathrm{D})$.

Let us consider the strength of cement samples based on activated water closure with addition Mecellose 22501 for tensile bending. Figure 7 shows the dependence of flexural tensile strength on the age of samples in days. Based on the results of the tests, it can be concluded that there are compositions whose results exceed the strength readings of the composition, based on non-activated water, taking into account the effect of the additive. Consider the strength set of each composition. We will analyze the tensile strength of the samples during bending.

Throughout the observation time, all compositions steadily gain strength in proportion to the theoretical model, no jumps and drops are observed. Let's consider the value of 
strength indices for 28 days. The results of the composition M3E1 + 0,6D are pronounced. Which showed a maximum tensile strength of $8.4 \mathrm{MPa}$.

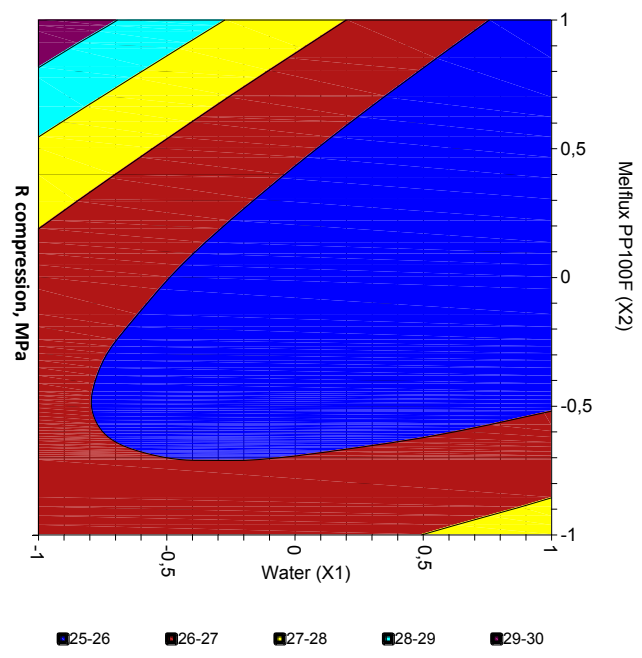

Fig. 6. Strength of cement samples under compression $\mathrm{f}(\mathrm{x})=\mathrm{Rcg}(\mathrm{t})$ plasticizer - MelFlux PP100F, 28 days (2D).

The average values for tensile bending strength are the compositions: M3E3 $+0.6 \mathrm{D}$, M3E3, M3E5 + 0.6D, M3E3 + 0.3D, M3E5 and M3E5 + 0.3D. The strength of the compositions ranges from $6.8 \mathrm{MPa}$ to $7.8 \mathrm{MPa}$.

The lowest results show compositions of M3E1, M3E1 + 0.3D. Their tensile strength is 5.6 $\mathrm{MPa}$ and 6.1 MPa, respectively.

Let us consider the strength of cement samples based on activated water closure with addition Mecellose 22501 for tensile bending. Figure 7 shows the dependence of flexural tensile strength on the age of samples in days. Based on the results of the tests, it can be concluded that there are compositions whose results exceed the strength readings of the composition, based on non-activated water, taking into account the effect of the additive. Consider the strength set of each composition. We will analyze the tensile strength of the samples during bending.

Throughout the observation time, all compositions steadily gain strength in proportion to the theoretical model, no jumps and drops are observed. Let's consider the value of strength indices for 28 days. The results of the composition M3E1 + 0.6D are pronounced. Which showed a maximum tensile strength of $8.4 \mathrm{MPa}$.

The average values for tensile bending strength are the compositions: $\mathrm{M} 3 \mathrm{E} 3+0.6 \mathrm{D}$, M3E3, M3E5 + 0.6D, M3E3 + 0.3D, M3E5 and M3E5 + 0.3D. The strength of the compositions ranges from $6.8 \mathrm{MPa}$ to $7.8 \mathrm{MPa}$.

The lowest results show compositions of M3E1, M3E1 + 0.3D. Their tensile strength is 5.6 $\mathrm{MPa}$ and 6.1 MPa, respectively [8]. 


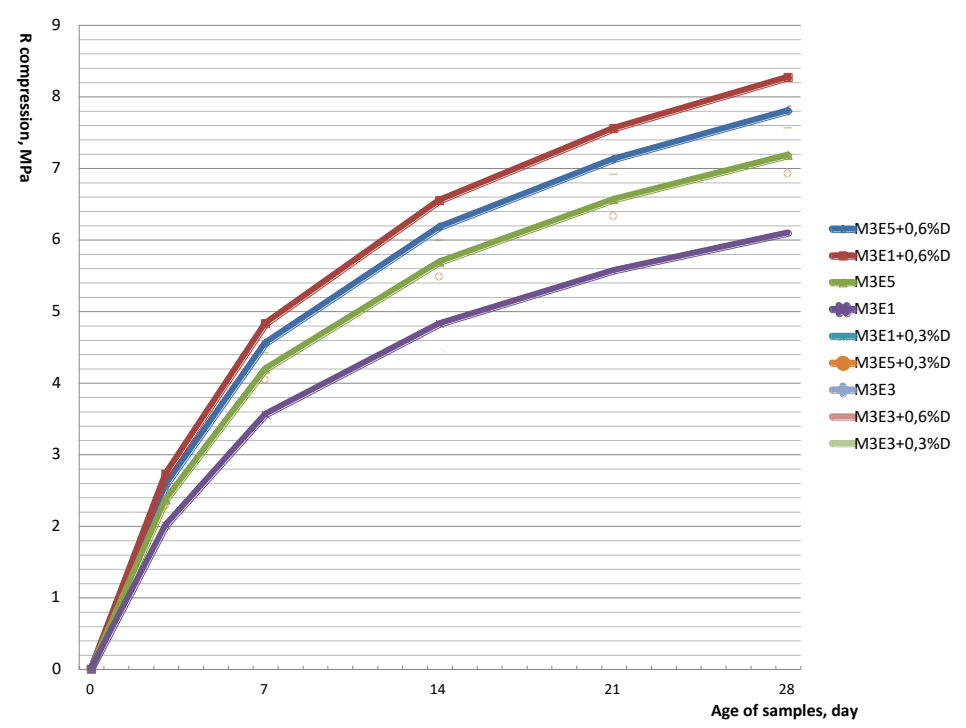

Fig. 7. Tensile strength of cement samples in bending, $f(x)=$ Rizg $(t)$ additive - Mecellose 22501 .

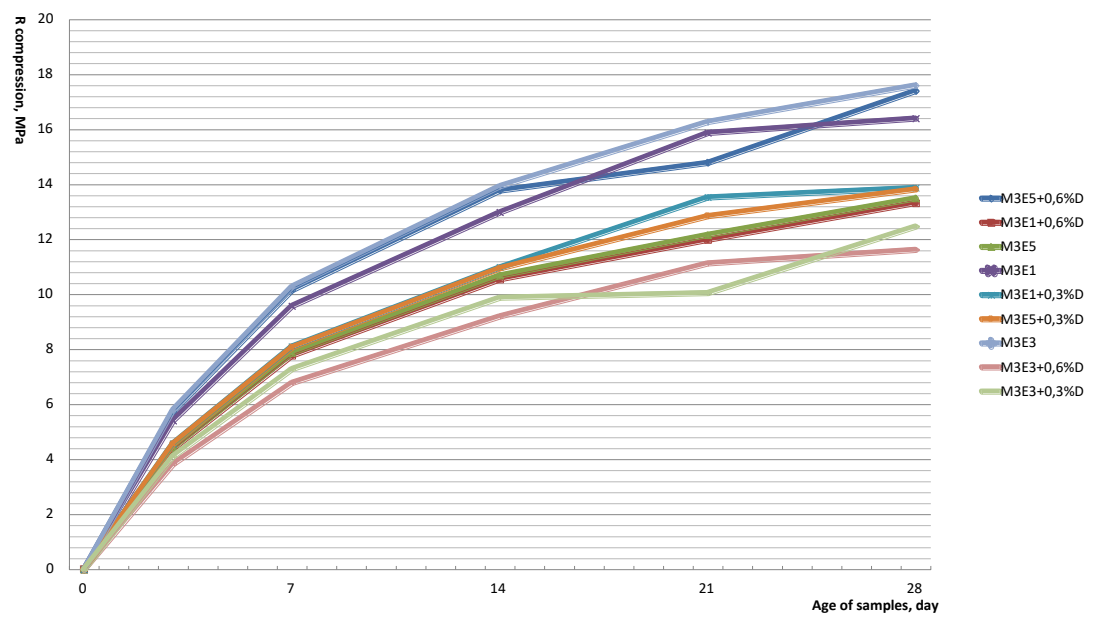

Fig. 8. Strength of cement samples for compression, $f(x)=R c g(t)$ additive - Mecellose 22501.

Consider the strength of cement samples based on activated water closure with Mecellose 22501 compression additive. Figure 8 shows the dependence of flexural tensile strength on the age of samples in days. Let's consider the value of strength indices for 28 days. Pronounced are the results of the compositions M3E3, M3E5 + 0.6D, M3E1. Their readings are the maximum value of compressive strength and range from $17 \mathrm{MPa}$ to $20 \mathrm{MPa}$.

The average values for compression strength are compositions: M3E5 + 0.3D, M3E1 + $0.3 \mathrm{D}, \mathrm{M} 3 \mathrm{E} 1+0.6 \mathrm{D}, \mathrm{M} 3 \mathrm{E} 5, \mathrm{M} 3 \mathrm{E} 3+0.3 \mathrm{D}$. The strength of the compositions ranges from $13 \mathrm{MPa}$ to $16.8 \mathrm{MPa}$.

The worst results showed the composition of M3E3 + 0.6D. Its compressive strength is $12 \mathrm{MPa}$. 
We will carry out statistical data processing in order to identify the optimal composition with the activation mode and the content of the additive.

Based on the planning matrix, we obtain a 2 -factor experiment with 2 variable factors: activation of water with a variable electric field (modes E1, E3, E5 with constant magnetic activation M3 = const) - factor Kh1 and the amount of additive -Kh2 used. Based on the obtained data using statistical data processing using a subroutine written in MS Excel 10, we obtain values of regression coefficients, substituting them and the equation we obtain a regression equation, the solution of which is the surface of Fig.9, 10. Based on the obtained volumetric solution, we can judge the influence of each of the variable factors on the investigated value of Fig.

Polynomial model:

$$
\operatorname{Rsg}(\mathrm{y})=12.844+0.825 \cdot \mathrm{x} 1+0.513 \cdot \mathrm{x} 2+1.744 \cdot \mathrm{x} 1 \cdot \mathrm{x} 2+2.683 \cdot \mathrm{x} 12-0.279 \cdot \mathrm{x} 22
$$

Let's analyze Figure 9. As mentioned above, the surface shown in the figure is a solution to the regression equation, and therefore the value of the ultimate compression strength of the test samples at the age of 28 days.

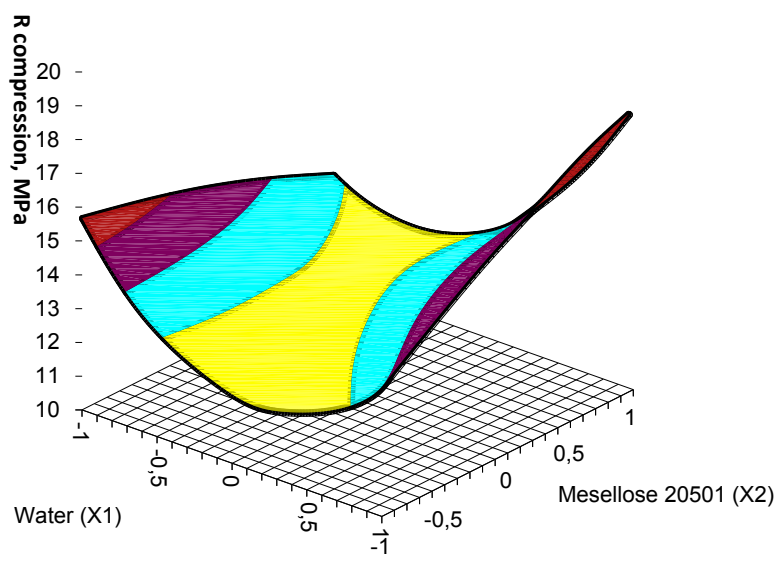

문-11 민1-12 미2-13 ㅁ13-14

Fig. 9. Compressive strength of cement molds $f(x)=\operatorname{Rsg}(t)$, additive-Mecellose 22501, 28 days (3D). 


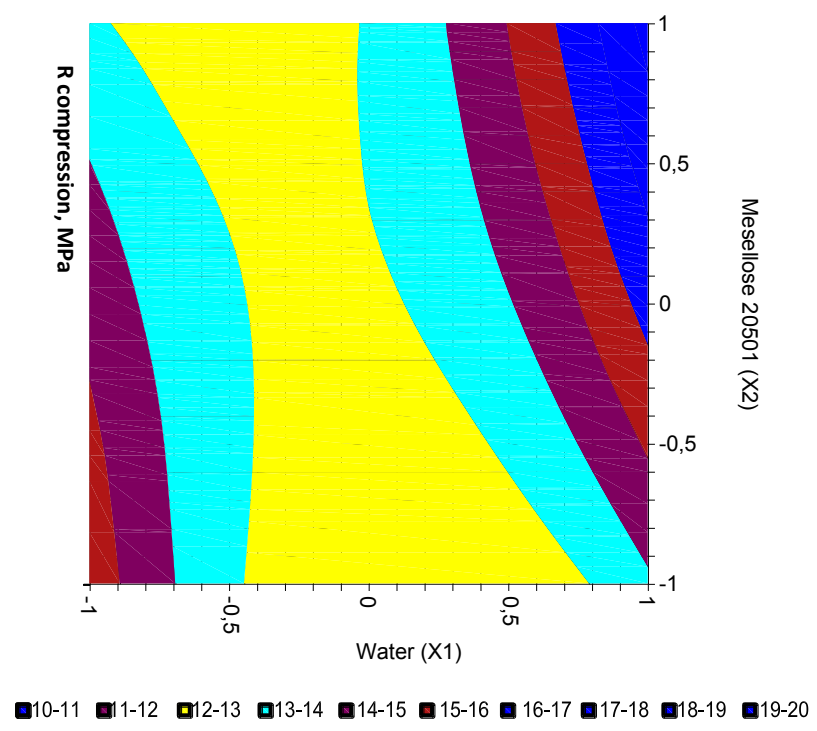

Fig. 10. Strength of cement samples under compression $\mathrm{f}(\mathrm{x})=\mathrm{Rcg}(\mathrm{t})$, additive - Mecellose 22501, 28 days (2D).

As can be seen from the graph, the maximum value of strength of cement samples during compression is achieved with water values $(\mathrm{Kh} 1)=-1$, Mecellose $22501(\mathrm{Kh} 2)=1$, which is equal to $\mathrm{Rgf}=20 \mathrm{MPa}$. With water values $(\mathrm{Kh} 1)=0$, Mecellose $22501(\mathrm{Kh} 2)=-0.5$, the strength is $\mathrm{Rcg}=13 \mathrm{MPa}$, which corresponds to the minimum value.

This pattern is optimal for cement samples is the composition of M3E1 + 0, 6D.

The worst are the compositions: M3E5 + 0, 3D and M3E5 + 0, 6D.

It can be concluded that the compositions M3E3, M3E5 + 0, 6D are the most optimal and stable for both bending tension and compression. The strength gain of the composition M3E3 for bending tension is $13 \%$, and for compression - $22 \%$. The strength gain of the composition M3E1 + 0, 6D for bending tension is $16 \%$, and for compression - $24 \%$.

\section{Conclusion}

The test results showed that the application of the technology of making cement compositions based on activated water closure led to a change in rheology towards increased mobility, as well as to an increase in the strength of these mixtures. It was found that in cement compositions prepared on activated water of the closure, mobility increases by $15-17 \%$, and strength - by more than $18 \%$. Application of this technology allows to achieve reduction of cement consumption by $7-10 \%$ without deterioration of concrete strength indices.

It is also necessary to note the most optimum modes of activation (on the basis of the device UPOVS-2/5.0 "Maksmir") for structures: - E1M3. In compositions with the addition of a plasticizer, samples showed themselves well: M3E1 + 0, 6D, M3E3 + 0, 6D, M3E5 + $0,6 \mathrm{D}$; using the additive: M3E1 + 0, 6D, M3E5 + 0, 6D.

Thus, it can be concluded that the most optimal is the joint activation of the gate water by magnetic field and electric current. This combination provides good stability of results and high strength.

Technical and economic efficiency of application of composite materials based on activated water closure 
The maximum value for compressive strength is the composition of M3E5, which is 42.8 $\mathrm{MPa}$. Select the appropriate concrete class according to Table 2.

Table 2. Dependence of concrete class on compressive strength of concrete samples.

\begin{tabular}{|l|l|}
\hline class & $\mathbf{R b}, \mathbf{M P a}$ \\
\hline $\mathrm{Bb} 30$ & 39.2 \\
\hline $\mathrm{Bb} 35$ & 45.7 \\
\hline $\mathrm{Bb} 40$ & 52.4 \\
\hline $\mathrm{Bb} 45$ & 58.9 \\
\hline $\mathrm{Bb} 50$ & 58.9 \\
\hline $\mathrm{Bb} 55$ & 72 \\
\hline $\mathrm{Bb} 60$ & 78.6 \\
\hline
\end{tabular}

Based on the above data, it can be noted that the corresponding class of concrete is $\mathrm{Bb} 30$. Its cost is 5,000 rubles. The cost of used concrete by us is 3852 rubles. The economic effect is 1.148 rubles or $22.96 \%$.

\section{Reference}

1. V.I. Klassen, Omagnetization of water systems (M, 1978)

2. E.A. Epstein, V.A. Rybakov, Engineering and Construction Journal, 4 (2009)

3. A.A. Matvievsky, E.A. Mitina, V.T. Erofeev, et al, Construction, architecture, design, 3 (7) (2009)

4. V. T. Erofeev, E. A. Mitin, V. V. Batin, et al., Study of the structure formation of cement composites on activated reclamation water, Topical issues of construction: materials, Vseros. Scientific - technical conf. Saransk, 418-422 (2006)

5. A.Y. Barmenkov, A.A. Matvievsky, Strength properties of cement composites on activated closing water during initial hardening periods (2021)

6. V. S. Lesovik. In the collection: intelligent building composites for green construction. International scientific and practical conference dedicated to the 70th anniversary of the Honored Scientist of the Russian Federation, 66-72 (2016)

7. A.S. Barmenkov, A.Y. Barmenkova, V.V. Lesnov, Water activation: abstracts, In the collection: Topical issues of architecture and construction. Proceedings of the Fourteenth International Scientific and Technical Conference: in 2 parts. Executive Editor V.T. Erofeev, 260-265 (2015)

8. A.S. Barmenkov, A strength properties of cement composites on activated water of closure in initial hardening periods. In the collection: Topical issues of architecture and construction. Proceedings of the Fourteenth International Scientific and Technical Conference: in 2 parts. Executive Editor V.T. Erofeev, 4-8 (2015) 